\title{
EXPERIÊNCIAS DE \\ RESGATE DA LÍNGUA \\ E CULTURA SAKURABIAT
}

\author{
Silvana da Silva Cunha GUARATIRA (D) \\ Secretaria de Estado de Educação de Rondônia (SEDUC-RO) \\ Carla Daniele Nascimento da COSTA (D) $\boldsymbol{X}$ \\ Universidade Federal do Pará (PPGL/UFPA)
}

\section{○}

OPEN ACCESS

EDITORES

- Marcus Maia (UFRJ)

- Bruna Franchetto (UFRJ)

\section{AVALIADORES}

- Hein Van der Voort (Museu Goeldi)

- Marcus Maia (UFRJ)

\section{SOBRE OS AUTORES}

- Silvana da Silva Cunha Guaratira Conceptualização, Recursos, Escrita - Análise e Edição.

- Carla Daniele Nascimento da Costa Curadoria de Dados, Investigação, Escrita - Rascunho Original.

DATAS

- Recebido: 07/06/2020

- Aceito: 07/10/2020

- Publicado: 28/12/2020

\section{COMO CITAR}

GUARATIRA, S.S.C; COSTA, C.D.N. (2020). Experiências de resgate da língua e cultura sakurabiat. Cadernos de Linguística, v. 1, n. 3, p. 01-14.

\section{RESUMO}

O povo indígena Sakurabiat vive tradicionalmente na região Norte do Brasil, no atual estado de Rondônia. Durante muitos anos, a língua Sakurabiat não foi aprendida pelas crianças. Atualmente, apenas os idosos e alguns adultos com mais de 50 anos falam a língua tradicional do povo, cerca de 12 pessoas, o que a coloca em sério risco de desaparecer. A maioria das línguas indígenas brasileiras encontra-se em situação de vulnerabilidade linguística (MOSELEY, 2010). Dessa maneira, as ações de resgate e valorização das línguas e culturas autóctones se fazem cada vez mais necessárias nas comunidades indígenas e na comunidade acadêmica. Visando agregar conhecimentos acerca de tais ações, este trabalho propõe-se a relatar experiências de resgate da língua e cultura Sakurabiat, com base no ensino da língua no contexto da educação escolar indígena. Tais experiências começaram a ser realizadas pelos Sakurabiat a partir da tomada de consciência do valor da língua tradicional para a comunidade, potencializada pelas reflexões e conhecimentos adquiridos a partir do ingresso de jovens Sakurabiat no curso de formação de professores indígenas (Projeto Açaí) da Secretaria de Estado de Educação de Rondônia (SEDUC-RO). Organização de festas tradicionais, oficinas de artesanatos e produção de atividades linguísticas na escola são algumas das ações realizadas pelos Sakurabiat para resgatar e valorizar a língua e cultura de seu povo. As experiências educacionais Sakurabiat evidenciam a importância de uma educação escolar indígena pautada na diversidade, capaz de motivar ações efetivas de valorização e resgate das línguas e culturas tradicionais. 


\section{ABSTRACT}

The indigenous people Sakurabiat traditionally live in the northern part of Brazil, in the current state of Rondônia. For many years, the Sakurabiat language was not learned by children. Nowadays, only elderly people and some adults of more than 50 years old speak the traditional language of the group, around 12 people, and is therefore in serious danger of disappearing. Most of the Brazilian indigenous languages are in a situation of vulnerability (MOSELEY, 2010). Consequently, salvage and promotion of the indigenous languages and cultures have become increasingly urgent in both the indigenous communities and the academic community. In order to prepare for initiatives in this regard, this article reports on experiences of Sakurabiat language and culture rescue, based on language teaching in the indigenous school context. The Sakurabiat people had such experiences when they became conscious of the value of the traditional language for the community. This was triggered especially by the participation of young Sakurabiat in the indigenous teacher training course (Açaí Project) set up by the Education Secretary of the State of Rondônia (SEDUC-RO). The organization of traditional festivities as well as crafts workshops and language activities in the school were among the activities by the Sakurabiat carried out in order to rescue and to promote their traditional language and culture. The Sakurabiat educational experiences demonstrate the importance of indigenous formal education based on diversity, capable of motivating effective actions of valorization and preservation of traditional language and culture.

\section{PALAVRAS-CHAVE}

Resgate Linguístico; Língua e Cultura Sakurabiat;

Educação Escolar Indígena.

\section{KEYWORDS}

Language Revitalization; Sakurabiat Culture and Language; Indigenous School Education. 


\section{INTRODUÇÃO}

Estima-se que há hoje no Brasil cerca de 154 línguas indígenas sendo faladas (STORTO, 2019). São línguas que resistiram, e ainda resistem, a um processo violento de colonização e consequente massacre de línguas e culturas autóctones. De acordo com o atlas mundial das línguas em perigo de extinção, desenvolvido pela Organização das Nações Unidas para a Educação, a Ciência e a Cultura (UNESCO), a maioria das línguas indígenas no Brasil está em situação de vulnerabilidade linguística; isto é, ameaçada de extinção.

A partir desse cenário, várias comunidades indígenas perceberam a necessidade de promover ações que colocassem em evidência suas línguas e culturas tradicionais. Tais ações ocorrem de forma diferenciada a depender das necessidades e do contexto de cada comunidade, e com isso acabam por receber nomeações distintas, como: revitalização, resgate, vitalização, retomada, fortalecimento etc. Apesar de terem nomes distintos e objetivos específicos, todas essas ações compartilham a realidade da maioria das comunidades indígenas no Brasil: pertencerem a comunidades linguísticas minorizadas que afirmam e reivindicam suas identidades indígenas a partir da valorização das línguas de seus ancestrais.

Buscando refletir e agregar conhecimentos sobre essa conjuntura, o presente trabalho tem por objetivo relatar experiências de resgate da língua e cultura Sakurabiat, com base no ensino da língua no contexto da educação escolar indígena. Para tanto, descrevemos o processo de tomada de consciência do valor da língua tradicional para a comunidade e as ações realizadas pelos Sakurabiat para resgatar e valorizar a língua e cultura de seu povo.

Este relato está organizado em seções. A seção atual introduz o assunto a ser discutido e identifica a estruturação do texto. Na seção seguinte apresentamos algumas características do povo e da língua Sakurabiat. A terceira seção é dedicada à reflexão sobre a formação de professores da etnia Sakurabiat e a valorização da língua e cultura do povo no contexto da educação escolar indígena. Na quarta seção tecemos as considerações finais, e na última seção apresentamos as referências bibliográficas.

\section{ALGUMAS CONSIDERAÇÕES SOBRE O POVO E A LÍNGUA SAKURABIAT}

O povo indígena Sakurabiat (Sakyrabiar, Sakyrabiá) vive tradicionalmente na região Norte do Brasil, no atual estado de Rondônia. A Terra Indígena (T.I.) Rio Mequens foi demarcada em 1996, e hoje tem cinco aldeias (90, Mariano, Baixa Verde, Soopipari e Kwai), que abrigam cerca de 74 indígenas Sakurabiat. O número de famílias não é muito grande, pois muitas 
pessoas faleceram por causa de epidemias e outros problemas. O mapa abaixo identifica as terras indígenas do estado de Rondônia. A Terra Indígena Rio Mequens está identificada com o número 3 e destacada com um círculo vermelho em volta.

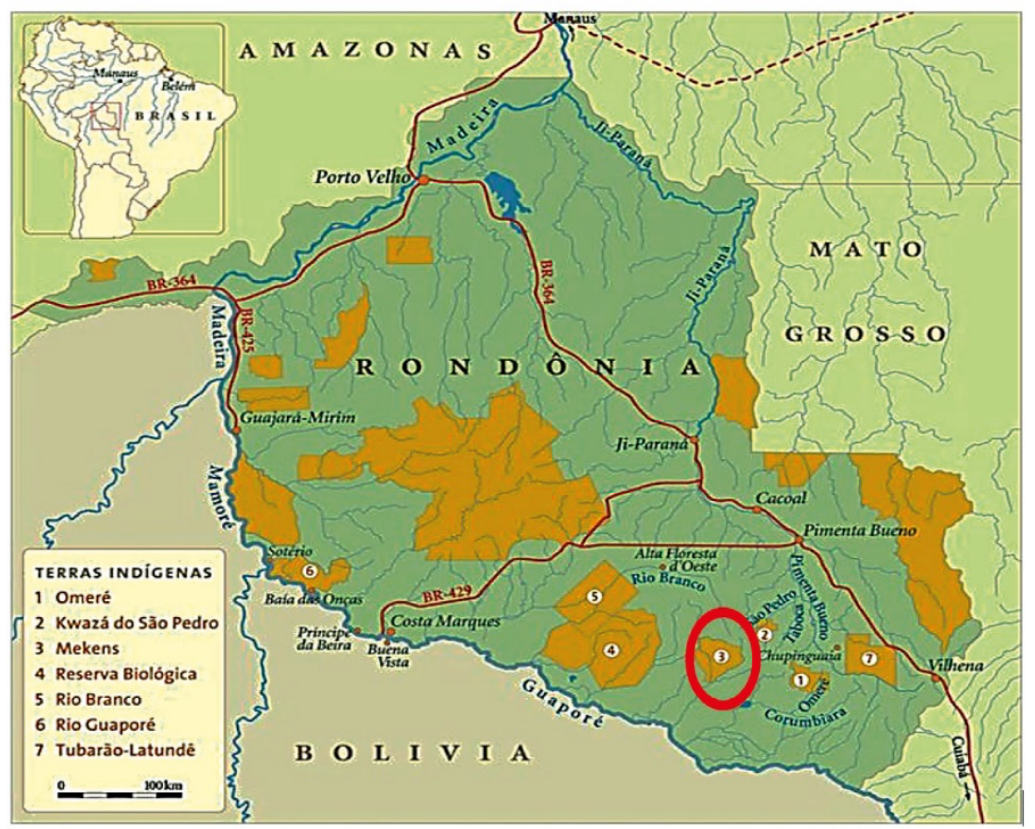

Figura 1. Terras Indígenas do Estado de Rondônia. Fonte: Voort (2004) - Adaptado.

Há duas décadas, aproximadamente, houve uma quebra na transmissão da língua Sakurabiat. Por conta disso, as crianças e jovens da comunidade passaram a usar o português como a principal língua para a comunicação diária. Atualmente, apenas os idosos e alguns adultos com mais de 50 anos falam fluentemente a língua tradicional do povo. São aproximadamente 12 pessoas, o que coloca a língua em sério risco de desaparecer.

Há vários fatores que podem levar à quebra na transmissão de uma língua. Sabemos que no Brasil, a invasão dos territórios indígenas e o consequente genocídio das populações tradicionais tem sido um dos principais fatores que contribuem para a perda de línguas e populações indígenas. Na comunidade Sakurabiat, os adultos na faixa-etária de 50-60 anos contam que houve uma época em que a comunidade sofreu com a invasão de seringueiros em suas terras. Durante esse período, muitos indígenas sofreram ameaças para pararem de falar a língua tradicional. Muito provavelmente a violência física também era utilizada como forma de coibir o uso da língua indígena. Acreditamos que dentre as várias ações, crenças e atitudes linguísticas que norteiam a manutenção ou extinção de uma língua, a associação da língua indígena às violências física e simbólica sofridas pelos mais velhos foi um dos motivos que levou à interrupção da transmissão intergeracional da língua Sakurabiat. 
Em um determinado momento da história, falantes Sakurabiat se viram obrigados a deixar de ensinar a língua indígena para seus filhos como uma forma de protegê-los de futuras violências. Também nesse período, a língua indígena sofreu vários tipos de caracterizações negativas por parte dos não indígenas. Ela era vista como inferior à língua portuguesa, muitas vezes tachada como "gíria", e qualificada como sendo "feia" e de difícil compreensão. Essas caracterizações deram origem a crenças linguísticas que dificultaram tentativas de resgate da língua Sakurabiat, propostas na década de 1990. A ideia de que o ensino de Sakurabiat dificultaria a aprendizagem de português pelas crianças foi uma das crenças reproduzidas por membros da própria comunidade. Crenças estas que resultaram em atitudes linguísticas extremas, como a proibição do uso da língua indígena em algumas casas.

Em termos de filiação genética, a língua Sakurabiat, juntamente com as línguas Wayoro, Akuntsu, Makurap e Tupari integram o ramo denominado Tupari, pertencente ao tronco Tupi. A palavra Sakurabiat é uma palavra composta (sakurap 'macaco-prego' + iat 'coletivo; plural') que significa literalmente 'grupo dos macacos-prego'. Nos dias de hoje, o termo Sakurabiat vem sendo usado para se referir tanto à língua, quanto ao povo que a fala.

Apesar do número populacional reduzido, bem como do número de falantes, a língua Sakurabiat conserva três variedades dialetais: Sakurabiat, Guaratira e Siokweriat. A variedade Siokweriat é representada por um único membro - um indígena Sakurabiat que mora na T.I. Rio Branco (identificada com o número 5, na figura 1, acima) - e sua fala é mais próxima da variedade Guaratira do que da variedade Sakurabiat (GALÚCIO, 2001). A autora esclarece que as três variedades são mutuamente inteligíveis, estando suas diferenças condicionadas, quase que exclusivamente, a variações de alguns itens lexicais, percebidas pelos falantes de cada grupo com uma certa regularidade. Como exemplo, podemos citar a ocorrência de consoantes nasais no dialeto Sakurabiat que correspondem a consoantes oclusivas surdas em Guaratira e Siokweriat; como nas palavras <mãkũyã > 'cutia' e <ngwã'ẽ> 'panela' no dialeto Sakurabiat, mas <pakũyã > 'cutia' e $<k w a ' e \tilde{s}$ 'panela' em Guaratira e Siokweriat.

No que diz respeito ao levantamento fonético e fonológico da língua Sakurabiat, Galúcio (2001) identificou 15 fonemas consonantais e 20 fonemas vocálicos, identificados nos quadros 1 e 2, a seguir: 


\begin{tabular}{|c|c|c|c|c|c|}
\cline { 2 - 6 } \multicolumn{1}{c|}{} & Labial & Alveolar & Palatal & Velar & Glotal \\
\hline Oclusivas & $\mathrm{p} \mathrm{b}$ & $\mathrm{t}$ & & $\mathrm{k}_{\mathrm{kw}}$ & ? \\
\hline Fricativa & & $\mathrm{s}$ & & & \\
\hline Líquida & $\mathrm{m}$ & $\mathrm{n}$ & & $\mathrm{\eta}$ & \\
\hline Nasais & $\mathrm{m}$ & & $\mathrm{j}$ & $\mathrm{j}^{\mathrm{w}}$ & \\
\hline Glides & $\mathrm{w}$ & $\mathrm{i}$ & & \\
\hline
\end{tabular}

Quadro 1. Inventário Fonológico das consoantes Sakurabiat. Fonte: Galúcio (2001, p. 22 - Adaptado)

\begin{tabular}{|c|c|c|c|c|c|c|}
\hline & \multicolumn{3}{|c|}{ Vogais orais curtas } & \multicolumn{3}{|c|}{ Vogais orais longas } \\
\hline & Anterior & Central & Posterior & Anterior & Central & Posterior \\
\hline Alta & $\mathrm{i}$ & $\dot{i}$ & & $\mathrm{i}:$ & $i:$ & \\
\hline Média & $\mathrm{e}$ & & $\mathrm{o}$ & e: & & 0 \\
\hline Baixa & & $a$ & & & $a:$ & \\
\hline & \multicolumn{3}{|c|}{ Vogais nasais curtas } & \multicolumn{3}{|c|}{ Vogais nasais longas } \\
\hline Alta & $\tilde{\imath}$ & $\tilde{t}$ & & ĩ: & $\tilde{\mathrm{t}}:$ & \\
\hline Média & ẽ & & $\tilde{o}$ & $\tilde{\mathrm{e}}:$ & & $\tilde{0}$ \\
\hline Baixa & & $\tilde{a}$ & & & $\tilde{a}$ & \\
\hline
\end{tabular}

Quadro 2. Inventário Fonológico das vogais Sakurabiat. Fonte: Galúcio (2001, p. 22 - Adaptado)

A primeira proposta de ortografia formal para a língua Sakurabiat foi organizada por Galúcio (2004). À época, a ortografia foi planejada para alfabetizar, em língua indígena, integrantes da comunidade que falavam Sakurabiat como primeira língua. Desde então, a situação sociolinguística e educacional na comunidade sofreu algumas mudanças. O número de jovens Sakurabiat - falantes de português como primeira língua - cresceu, e alguns desses jovens tiveram acesso ao curso de formação de professores indígenas, denominado Projeto Açaí, ofertado pela Secretaria de Estado de Educação de Rondônia (SEDUC-RO). O ingresso no curso de formação de professores fez com que esses jovens Sakurabiat buscassem aprender a língua indígena para que pudessem ensiná-la às crianças da comunidade, principalmente aos alunos da escola indígena Aipere. Visando atender a esse público, Costa (2020) propôs uma adaptação da ortografia de 2004.

As principais mudanças propostas por Costa (2020) dizem respeito à grafia de vogais nasais e nasalizadas, vogais longas e suas representações maiúsculas e minúsculas. Na ortografia elaborada por Galúcio (2004), apenas as vogais fonologicamente nasais eram marcadas com o til < > . As vogais nasalizadas não recebiam essa marcação pois o espalhamento de nasalidade era previsto pelos falantes da língua. No entanto, o espalhamento de nasalidade não é previsível para os aprendentes de Sakurabiat como segunda língua. Por esse motivo, na ortografia atual, optou-se por marcar com o til as vogais nasalizadas, bem como as vogais fonologicamente nasais. Dessa forma, uma palavra como /pã.ra. 're/ 'peneira', pronunciada [pã.rã. 'rẽ], era escrita <pãrare> de acordo com a ortografia de Galúcio (2004) e passou a ser escrita <pãrãrẽ>, conforme a ortografia proposta por Costa (2020).

Outra mudança em relação à grafia de vogais nasais diz respeito à marcação com o til nas vogais nasais longas. De acordo com Galúcio (2004), as vogais longas são representadas ortograficamente por duas letras idênticas, como em /kũ : p/ 'doce', escrito <kũup>. No entanto, na representação ortográfica das vogais nasais longas a marcação com o 
diacrítico til só ocorre na primeira letra. Buscando manter a diferença entre vogais curtas e longas, e vogais nasais e orais, Costa (2020) propõe que as vogais longas nasais sejam grafadas por duas letras idênticas com o acréscimo do til nas duas letras, resultando na seguinte representação da palavra 'doce': <kũũp>. Ademais, a autora também propõe que as vogais longas, nasais e orais, sejam escritas por duas letras idênticas tanto na forma maiúscula quanto na forma minúscula. Sendo assim, um texto que inicie com a palavra /ã : po/ 'banco' deve começar da seguinte maneira: <Ã̃̃po>; e não <Ãapo> como previsto por Galúcio (2004). No quadro a seguir, temos os fonemas da língua Sakurabiat e suas respectivas representações ortográficas, de acordo com o proposto por Costa (2020).

\begin{tabular}{|c|c|c|}
\hline Fonema & Grafia maiúscula & Grafia minúscula \\
\hline$/ p /$ & $\langle\mathrm{P}\rangle$ & $<p>$ \\
\hline /b/ & $<B>$ & $<b>$ \\
\hline$/ \mathrm{t} /$ & $\langle\mathrm{T}\rangle$ & $<t>$ \\
\hline $\mid \mathrm{k} /$ & $<\mathrm{K}\rangle$ & $<\mathrm{k}>$ \\
\hline$/ \mathrm{k}^{\mathrm{w}} /$ & $\langle K w\rangle$ & $<k w>$ \\
\hline $\mathrm{lg} /$ & $\langle\mathrm{G}\rangle$ & $\langle g\rangle$ \\
\hline$/ 3 /$ & $<1>$ & $\langle>\rangle$ \\
\hline$|\mathrm{s}|$ & $\langle\mathrm{S}\rangle$ & $\langle s\rangle$ \\
\hline$|r|$ & $<\mathrm{R}\rangle$ & $\langle r\rangle$ \\
\hline$/ \mathrm{m} /$ & $<\mathrm{M}\rangle$ & $<m>$ \\
\hline $\ln /$ & $\langle\mathrm{N}\rangle$ & $<\mathrm{n}>$ \\
\hline $\mid \mathrm{n} /$ & $<\mathrm{Ng}>$ & $<\mathrm{ng}>$ \\
\hline $\mid \mathrm{n}^{\mathrm{w}} /$ & $<\mathrm{Ngw}\rangle$ & $<n g w>$ \\
\hline$|w|$ & $\langle\mathrm{W}\rangle$ & $<W>$ \\
\hline /i/ & $\langle\mathrm{Y}\rangle$ & $<y>$ \\
\hline$|a|$ & $<A>$ & $<a>$ \\
\hline $\mid \tilde{a} /$ & $<\tilde{\mathrm{A}}>$ & $<\tilde{a}>$ \\
\hline $1 a: 1$ & $<A A>$ & $<a a>$ \\
\hline |ã : / & $<\tilde{A} \tilde{A}>$ & $<\tilde{a} \tilde{a}>$ \\
\hline $\mid \mathrm{e} /$ & $<\mathrm{E}>$ & $<e>$ \\
\hline |е̃/ & $<\tilde{E}>$ & $<\tilde{\mathrm{e}}>$ \\
\hline /e:/ & $<\mathrm{EE}>$ & $<\mathrm{ee}>$ \\
\hline /ẽ:/ & $<\tilde{E} \tilde{E}>$ & <ẽẽ $>$ \\
\hline /i/ & $<1>$ & $<i>$ \\
\hline $\mid \tilde{\mathrm{I}}$ & $\langle\bar{l}>$ & $<\tilde{\mid}>$ \\
\hline $\mid \mathrm{i}: /$ & $<\|>$ & $<\mathrm{ii}>$ \\
\hline$/ \tilde{\imath}: /$ & $<\pi \Pi>$ & $<i>$ \\
\hline /i/ & $\langle U\rangle$ & $\langle U\rangle$ \\
\hline$\tilde{\mathrm{t}}$ & $<\tilde{U}>$ & $<\tilde{\mathrm{U}}>$ \\
\hline$|\mathrm{i}:|$ & $\langle U U\rangle$ & $<U U>$ \\
\hline$\tilde{\mathrm{f}}: /$ & $<\tilde{U} \tilde{U}>$ & $<$ <ũ̃ > \\
\hline $10 /$ & $\langle\mathrm{O}\rangle$ & $\langle 0\rangle$ \\
\hline | & $\langle\tilde{\mathrm{O}}\rangle$ & $<\tilde{0}>$ \\
\hline $10: 1$ & $\langle\mathrm{OO}\rangle$ & $<00\rangle$ \\
\hline |õ:| & $<\tilde{O O O}>$ & <õõ> \\
\hline
\end{tabular}

Quadro 3. Representação ortográfica dos fonemas Sakurabiat. Fonte: As autoras (2020).

Como discutido em Costa e Galúcio (2019), a modalidade escrita da língua Sakurabiat possui status elevado na comunidade. Materiais escritos na língua indígena, como o livro de narrativas tradicionais Sakurabiat: Mayãp ebõ (GALÚCIO, 2006) e a cartilha de alfabetização (GALÚCIO; SAQUIRABIAR, 2004), são bastante conhecidos por toda a comunidade e serviram como importante ferramenta de pesquisa para que os professores indígenas em formação pudessem suprir necessidades de uso da língua em atividades escolares. 
Questões sobre a formação dos professores indígenas Sakurabiat, bem como o uso da língua indígena em contextos educacionais, são apresentadas na próxima seção.

\section{FORMAÇÃO DE PROFESSORES INDÍGENAS E REFLE- XÕES SOBRE O PROCESSO DE RESGATE LINGUÍSTICO E CULTURAL}

A educação escolar indígena no Brasil, tal qual conhecemos hoje, é resultado de um longo processo de luta dos povos indígenas para garantir o direito a uma educação diferenciada, pautada na valorização das línguas e culturas autóctones. Até 1970, a escolarização indígena servia como uma ferramenta para a assimilação e consequente apagamento dos povos indígenas no Brasil. É só a partir da Constituição Federal de 1988, através dos artigos 210 e 231, que o Estado reconhece pela primeira vez as especificidades dos povos tradicionais em sua organização social, processos próprios de aprendizagem, usos, costumes, línguas e tradições.

A partir do marco estabelecido pela Constituição de 1988, a educação escolar indígena no Brasil caracteriza-se como uma política pública que começa a ganhar forma através de uma série de documentos legais, como a Lei de Diretrizes e Bases de Educação (LDB, Lei 9394/96) que em seus artigos 78 e 79 ressalta a importância do fortalecimento das práticas socioculturais e a língua materna de cada comunidade, assim como programas de formação de pessoal especializado destinado à educação escolar nas comunidades indígenas. Outro documento importante é o Referência Curricular Nacional para Escolas Indígenas (RCNEI) de 1998, que estabelece a interculturalidade, o bi/multilinguismo e os caráteres comunitário, diferenciado e específico como fundamentos da educação escolar indígena no Brasil. É a partir desses fundamentos que ações como a formação de professores indígenas passam a ser elaboradas com vistas a garantir que a escola indígena cumpra seu papel em valorizar as línguas e culturas dessas comunidades.

O processo de resgate da língua e cultura Sakurabiat teve seu início a partir da tomada de consciência da importância das línguas indígenas pelos próprios indígenas. Isso se deu, principalmente, a partir de aulas e conversas com professores do curso de formação de professores indígenas a nível de magistério - Projeto Açaí - da SEDUC de Rondônia.

Como resultado de muita luta do movimento indígena em Rondônia, o Projeto Açaí foi instituído pelo Governo do Estado através do Decreto n. 8.516, de 1998. O principal objetivo do projeto é ofertar a formação de professores indígenas, buscando desenvolver as habilidades necessárias ao exercício docente para que tais profissionais possam atuar nas 
escolas indígenas, atendendo às necessidades educacionais de alunos dos anos iniciais do ensino fundamental I (primeiro ao quinto ano).

A terceira turma do Projeto Açaí (denominada Projeto Açaí III) teve duração de quatro anos e meio (fevereiro de 2015 a setembro de 2019). Durante esse período, os alunos cursaram 3.650 horas/aula dispostas em 10 módulos presenciais de curso intensivo. Mais de 80 indígenas de diversas etnias do estado de Rondônia integraram a turma e colaram grau no dia 17 de setembro de 2019, dentre eles três indígenas Sakurabiat (Silvana, Ademildo e Arlete), incluindo a primeira autora deste relato.

Em conformidade com princípios como a interculturalidade e o bi/multilinguismo, as atividades desenvolvidas dentro do Projeto Açaí buscam estabelecer um diálogo entre os saberes indígenas e os não indígenas. Dessa forma, os professores das diversas disciplinas incentivam os cursistas a tornarem-se professores-pesquisadores de sua própria cultura. Atividades envolvendo aspectos da língua e cultura dos alunos são requeridas durante as aulas através da apresentação de palavras nas línguas indígenas, seja em sua modalidade oral ou escrita, e de aspectos culturais, como artesanatos, histórias tradicionais, danças etc. As turmas do Projeto Açaí geralmente são bastante heterogêneas, englobam desde alunos falantes fluentes de sua língua tradicional, até aqueles que aprenderam português como primeira e única língua. Nesse último caso, as atividades que demandam saberes tradicionais se tornam oportunidades para que os alunos busquem tais conhecimentos em suas comunidades através dos anciões e conhecedores da língua e cultura.

Em 2015, quando iniciaram o curso de formação de professores, os alunos Sakurabiat sentiram muita dificuldade nas atividades que demandavam conhecimentos sobre a língua indígena. Sendo falantes de português como primeira língua, e tendo apenas conhecimento de algumas palavras referentes a nomes de animais e plantas em Sakurabiat, os três cursistas - ao se depararem com colegas de classe que falavam fluentemente a língua de seu povo, bem como com professores que incentivavam a valorização das línguas e culturas indígenas - começaram a perceber a importância que as línguas e culturas indígenas possuem na construção da identidade étnica dos povos.

A partir dessa tomada de consciência, os três alunos Sakurabiat decidiram se unir e começar um movimento de resgate da língua e cultura de seu povo. Com o incentivo e ajuda de uma das professoras do Projeto Açaí, os jovens organizaram uma festa para resgatar conhecimentos culturais do grupo, como a preparação de comidas tradicionais e de artesanatos. Durante a organização e realização da festa, no entanto, o grupo de jovens percebeu que muitos saberes estavam adormecidos na memória dos mais velhos. Algumas pessoas lembravam vagamente como preparar determinadas comidas e poucas pessoas conseguiam lembrar como confeccionar os artesanatos tradicionais. Ficou evidente, então, que a comunidade carecia de mais espaços de uso da língua e cultura para que os conhecimentos tradicionais não fossem perdidos. 
Buscando aprimorar os conhecimentos adquiridos na primeira festa e visando desenvolver espaços de uso da língua e cultura Sakurabiat, os três alunos do curso Açaí conversaram com os caciques e os outros membros da comunidade para juntos fazerem uma segunda festa. Nessa segunda ocasião, os pais dos alunos indígenas tiveram um papel muito importante. Como uma forma de preparação para a festa, Rosalina e Severino Guaratira relembraram memórias de infância, de atividades que faziam com seus pais, e repassaram esses saberes aos primos Ademildo e Silvana, que juntos sistematizaram tais informações e com o apoio da comunidade realizaram a segunda festa. Dessa vez, artesanatos como brincos, pulseiras e colares começaram a ser confeccionados, e a alimentação durante a festa incluiu vários tipos de comidas tradicionais, como: massaco ${ }^{1}$ de mandioca e cará, chicha $^{2}$ de banana e milho, carne moqueada ${ }^{3}$, peixe assado na folha de bananeira etc.

O uso da língua Sakurabiat também ficou mais evidente na segunda festa. As pessoas começaram a falar, em Sakurabiat, os nomes dos animais, frutas e cereais usados na preparação das comidas tradicionais, bem como dos elementos da fauna e flora utilizados para a confecção dos artesanatos. Todos da comunidade participaram de alguma forma, o que fez com que a festa tivesse êxito e fosse muito elogiada.

Outra importante experiência para a comunidade Sakurabiat foi a oficina de artesanato que aconteceu em julho de 2017. Os três alunos do Projeto Açaí, com o auxílio da Coordenação Regional da Funai de Cacoal (RO), articularam uma grande reunião na aldeia Baixa Verde para a troca de experiências com indígenas de outras etnias do estado de Rondônia (Aikanã, Surví e Cinta Larga). Ao todo, foram três dias de atividades, incluindo oficinas de artesanato, como produção de rede e flecha, pintura corporal, canto e danças das etnias presentes.

1 Comida tradicionalmente feita com um tipo de carne e um tubérculo (mandioca, cará), ou banana, fritas e amassados juntos no pilão até formar uma massa compacta.

2 Tipo de bebida que pode ser feita de cereais e legumes, como o milho, cará, mandioca etc. Há dois principais tipos de chicha: a doce, assemelha-se a uma garapa ou suco, e a chicha azeda - que sofre processo de fermentação natural.

3 Moquear é a técnica de assar carne em uma grelha de madeira apoiada sobre forquilhas (também de madeira) fincadas ao solo em volta de uma fogueira baixa. 


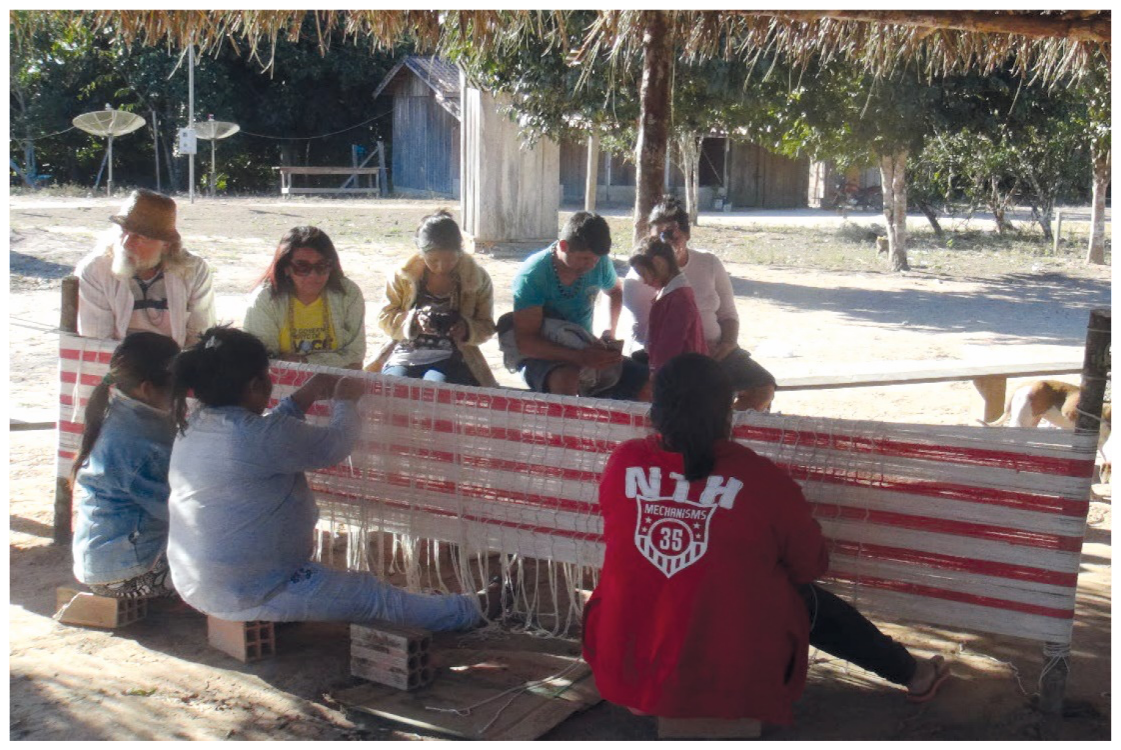

Figura 2. Mulheres Sakurabiat tecendo rede. Fonte: acervo das autoras.

\subsection{O PAPEL DA ESCOLA INDÍGENA AIPERE NA VALORIZAÇÃO DA LÍNGUA E CULTURA SAKURABIAT}

Como já mencionado neste texto, a Terra Indígena Rio Mequens está organizada, atualmente, em cinco aldeias. No entanto, apenas em uma delas - na aldeia Baixa Verde - há uma escola indígena em funcionamento, com aulas regulares e uma professora da comunidade contratada pela SEDUC de Rondônia. É na escola Aipere que a professora Silvana Guaratira desenvolve atividades de valorização e resgate da língua e cultura Sakurabiat. Essas atividades são planejadas de acordo com o que a professora aprende a respeito da língua e cultura de seu povo com os mais velhos da comunidade, principalmente com seu pai (falante fluente da língua) que também é avô e pai de alunos da escola. A partir dos conhecimentos que adquire, a professora ensina aos alunos da aldeia Baixa Verde sobre os costumes antigos e a língua tradicional do povo.

A participação da comunidade em atividades da escola tem sido fundamental para o desenvolvimento de ações de resgate da língua e cultura Sakurabiat, promovidas pela professora indígena. O pai da professora auxilia a filha contando histórias tradicionais Sakurabiat para os alunos, bem como fazendo caminhadas à floresta para ensinar os aprendizes sobre plantas medicinais. Além disso, as famílias da comunidade incentivam as crianças a utilizar palavras em Sakurabiat dentro de casa (principalmente às de fauna e flora), colaborando assim para o trabalho da professora na escola.

Tais atividades têm se mostrado importantes para a conscientização do grupo em relação à valorização da língua indígena como um importante elemento da identidade Sakurabiat. Antes das ações realizadas pela professora, as famílias da comunidade pouco estimulavam as crianças a aprenderem como falar na língua Sakurabiat 
palavras do cotidiano da aldeia. Após conversas da professora com os membros da comunidade a respeito da importância da língua Sakurabiat como símbolo da identidade étnica do grupo, além das atividades de uso da língua indígena realizadas dentro e fora da escola, os pais começaram a ensinar aos filhos nomes de animais, frutas, utensílios do dia a dia etc., em Sakurabiat.

A professora considera que houve uma mudança significativa na comunidade nos últimos anos. Ela recorda que, quando criança, teve pouquíssimas oportunidades de contato com a língua indígena, mesmo seu pai sendo falante fluente dela. Hoje em dia, seu pai ajuda a ensinar Sakurabiat na escola, conta histórias antigas para as crianças e ensina a língua indígena para seus netos.

Complementar a essas ações, a professora ensina a ortografia da língua Sakurabiat na escola. As palavras em Sakurabiat aprendidas na comunidade estimulam atividades de leitura e escrita, como a produção de cartazes com desenhos e nomes na língua indígena. Esses materiais pedagógicos compõem o ambiente da escola indígena Aipere, como vemos abaixo:

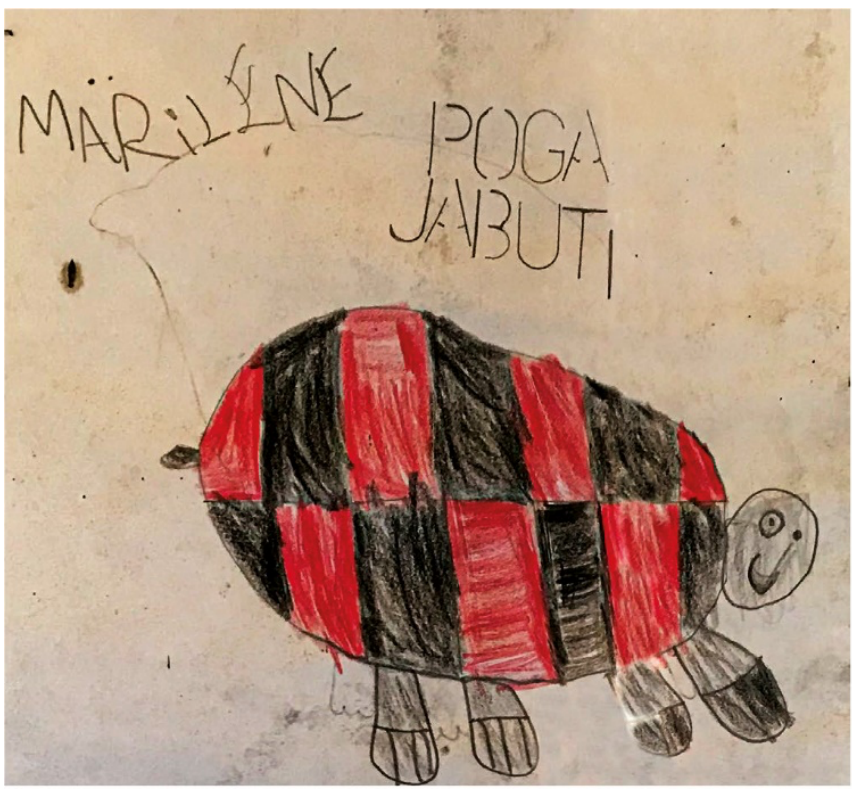

Figura 3. Desenho de um jabuti e seu nome em Sakurabiat (poga). Fonte: acervo das autoras.

Nesta seção, pudemos perceber que a formação dos professores Sakurabiat desencadeou importantes reflexões sobre a valorização das línguas e culturas indígenas, o que propiciou uma série de ações na comunidade, incluindo no contexto escolar, que tiveram como objetivo resgatar conhecimentos linguísticos e culturais do povo Sakurabiat. Na seção a seguir apresentamos algumas considerações acerca da experiência relatada neste texto e sua relação com a educação escolar indígena. 


\section{CONSIDERAÇÕES FINAIS}

Se no passado a escolarização de indígenas serviu como manobra para a assimilação de suas línguas e culturas, hoje ela tem sido ressignificada como uma escola indígena diferenciada, intercultural, comunitária e bi/multilíngue. Ainda há muito o que fazer para conseguir implementar na prática os fundamentos da educação escolar indígena no Brasil. Calendários flexíveis, currículos adequados a cada contexto e comunidade, formação continuada de professores indígenas e elaboração e publicação sistemática de materiais didáticos são alguns exemplos de ações que precisam ser implementadas de maneira organizada e contínua para garantir que as escolas indígenas pertençam - de fato - as suas comunidades.

A experiência Sakurabiat nos mostra que a educação escolar indígena pode funcionar como uma importante ferramenta no processo de valorização das línguas tradicionais. Para que isso ocorra, a formação adequada e continuada de professores, assim como de outros membros da comunidade, é fundamental. As ações de retomada linguística e cultural podem ser incentivadas a partir de ambientes escolares, mas, para que tais ações consigam alcançar seus objetivos, é necessário que a comunidade se envolva de tal forma nessas iniciativas que a língua e a cultura ultrapassem as fronteiras da escola e consigam se estabelecer nas práticas cotidianas de toda a comunidade.

\section{REFERÊNCIAS}

BRASIL. Constituição (1988). Constituição da República Federativa do Brasil. Brasília: Senado Federal. 1988.

BRASIL. Referencial Curricular Nacional para as Escolas Indigenas. Brasília: MEC/SEF, 1998, p. 339.

BRASIL. Lei 9394/1996 de 20 de novembro de 1996. Lei de Diretrizes e Bases da Educação Nacional. Brasília: MEC, 1996. Disponível em: http://www.planalto.gov.br/ccivil_03/Leis/L9394.htm. Acesso: 6 nov. 2017.

COSTA, C. D. N. Proposta de Material Didático para a Língua Sakurabiat. 160 f. Dissertação (Mestrado) Programa de Pós-graduação em Letras, Universidade Federal do Pará, Belém, 2020.

COSTA, C. D. N.; GALÚCIO, A. V. O status da escrita no contexto educacional da língua Sakurabiat. Entrepalavras, Fortaleza, v. 9, n. 2, p. 415-433, maio-ago. 2019. DOI http://dx.doi.org/10.22168/2237-632121507.

GALUCIO, A. V. The Morphosyntax of Mekens (Tupi). $260 \mathrm{f}$. Tese (Doutorado) - Departamento de linguística, Universidade de Chicago, Chicago, 2001.

GALUCIO, A. V. Justificativa Formal da Ortografia Sakurabiat (Mekens). Belém: MCT/MPEG, 2004.

GALUCIO, A. V. Narrativas Tradicionais Sakurabiat: Mayãp Ebõ. Belém: MPEG, 2006.

GALUCIO, A. V.; SAQUIRABIAR, O. F. Sakurabiat Erek Ninga: alfabetização na língua Sakurabiat (Mekens). Belém: MPEG, 2004.

MOSELEY, C. (ed.) Atlas of the World's Languages in Danger. 3 ed., Paris: UNESCO, 2010. Disponível em: http://www.unesco.org/languages-atlas/index.php. Acesso em: 13 nov. 2017. 
RONDONIA. Decreto $n^{\circ}$ 8.516, 15 de outubro de 1998. Institui o Curso de Formação de Professores Indígenas Habilitação em Magistério Nível Médio, denominado Projeto Açaí, e dá outras providências. Rondônia: Casa Civil, 1998. Disponível em: http://ditel.casacivil.ro.gov.br/COTEL/Livros/Files/D8516.pdf. Acesso em: 25 mai. 2020.

STORTO, L. Línguas Indigenas: tradição, universais e diversidade. Campinas: Mercado de Letras, 2019.

VOORT, H. A grammar of Kwaza. Berlin: Mouton de Gruyter, 2004. 